\title{
Regional analysis and sustainable development: Application of a synthetic sustainability indicator to Galicia and the European Union
}

\author{
Federico Martín-Palmero, Fernando González-Laxe \\ (Facultad de Ciencias Económicas y Empresariales, Universidad de A Coruña, A CORUÑA 15071, Spain)
}

\begin{abstract}
In general, investigations carried out to date regarding/measuring systems/systems of measurement of sustainable development present two peculiarities: Either they are of a limited practical nature or they do not allow for comparisons between different areas or economies. Global synthetic indicators are an exception to the above; however they have been scarcely developed. This article designs an index of said characteristics, which is subsequently applied to all the countries within the European Union and to the region of Galicia.
\end{abstract}

Key words: sustainable development; regional analysis; Spain; European Union

\section{Introduction}

The term sustained development was coined in the eighties, which gave rise to considerable economic literature. In the same manner, an enormous amount of investigations appeared aimed at creating methodologies and proposing alternatives to traditional methods-generally speaking of a quantitative and monetary nature - in order to determine whether the path of economic development was compatible with sustainability. In consequence, it was a question of putting into practice accounting systems that were compatible with and based upon principles of sustainable development, in order to verify the fulfillment of the aforesaid principles. In any event, if the theoretical concept is still subject to open debate, its empirical analysis - although advanced - is the object of discussion and controversy.

In the first place, there have been numerous attempts at establishing methodological approximations and quantification systems in order to generate sustainability indexes normally classified as strong or very strong. Within this category, the following classification of indicators may be established (Jiménez Herrero, 2000; Martínez-Alier, 1999).

(1) Efficiency of economic - ecological services

(2) Environmental equilibrium

(3) Material

a. Material efficiency indicators

b. Energetic efficiency indicators (EROI)

(4) Biological and Physical synthetic

a. Human appropriation of net primary production (HANPP)

Federico Martín-Palmero, Ph.D., Facultad de Ciencias Económicas y Empresariales, University de A Coruña; research fields: sustainable development, economic theory.

Fernando González-Laxe, Ph.D., Facultad de Ciencias Económicas y Empresariales, University de A Coruña; research fields: regional economics, economy of natural resources. 


\section{b. Materials consumed directly and indirectly in each productive service unit (MIPS)}

The aforesaid sustainability measurements are very complex and are of limited practical application. On the other hand, the most extensive development of indicators has been carried out to measure weak sustainability typical of neoclassical analysis - and sensible sustainability (the latter definition was coined by Serageldin, 1996A, 1996B), although, in some cases valuation systems which are typical of strong sustainability are used. The reason lies in the availability and use of data in the form of traditional accounting and statistics. In this sense, the advances that have been made in the calculations of synthetic sustainability indexes, both simple and global, should be highlighted.

In the first of the aforementioned categories (simple synthetic), the four most developed indexes should be outlined: ISEW (Index of Sustainable Economic Welfare), GPI (Genuine Progress Indicator), SDP (Sustainable net Domestic Product) and EF (Ecological Footprints). The content of each index will be dealt with as follows:

ISEW. - The Index of Sustainable Economic Welfare was propounded by Daly and Cobb (1989), based on the initial contributions of Nordhaus and Tobin (1972). The ISEW is calculated by correcting GDP figures, including inequalities, household work and depreciation of natural capital. Various empirical approximations using similar methodologies have been carried out in order to calculate the index. The most complete work, from a geographical and temporal perspective, was carried out by Jackson and Stymne (1996). They analyzed the different valuations of GDP and ISEW and their evolution from 1950 to 1992 in different countries such as the United States, Germany, Sweden, Austria, United Kingdom and the Netherlands. In general until the seventies, with the exception of the Netherlands, GDP and ISEW evolved in a parallel manner, however henceforth the Index of Sustainable Economic Welfare decreases or, if it increases it does so in a lesser proportion than GDP. With a very polished methodology, Castañeda (1999) analyses the evolution of both variables in Chile from 1965 to 1995 to find that until 1980 they flow in a parallel manner and as of said year the ISEW begins to decrease, creating an important gap between GDP and the aforementioned index of sustainability.

GPI. - The Genuine Progress Indicator (GPI) responds to an identical concept as ISEW, with slight methodological modifications introduced by Cobb and Halsted in 1994 (Bermejo, 2001, p. 276).

SDP. - The Sustainable net Domestic Product is based on a correction methodology of National Income as proposed by Hueting and Bosch (1990). Through certain predefined standards of sustainable development, the cost of reaching said standards is calculated and subtracted from National Income. It is a complex method for measuring sustainability, and as a result, of limited practical application (Bermejo, 2001, p. 280).

EF. - The Ecological Footprints indicator, intimately related to the Carrying Capacity concept, is perhaps more rooted in strong sustainability as it substitutes monetary term measurements for those of physical space. Those who introduced the concept and the methodology to obtain it (Wackernagel \& Rees, 1996) try to determine - on the basis of current technology - which physical area could sustain a given population indefinitely and which is the area that is currently occupied (Martínez Alier, 1999, p. 62). The difference between the occupied area and the area theoretically defined as sustainable, could be used to measure a deficit or surplus, which would mark the observed disequilibrium (Bermejo, 2001, p. 283). The equalization of said disequilibrium - which was analyzed for open economies by Proops, et al (1999) - would be obtained by virtue of the international trade of goods with an ample content in natural resources.

Regarding the second category of indicators (global synthetic indexes), note should previously be taken of the attempts to standardize the new measurements made by international organizations such as the OECD (Bermejo, 2001, p. 270), which presented in 1991, together with the Canadian government, a proposal of 
sustainability indicators. It should be pointed out that the first exhaustive concretions are established by the aforesaid organization through its publication of sustainability indicators (OECD, 1998) that are divided into two categories: environmental (composed of 9 indicators) and socio-economic, distributed into 6 indicators. In total it contemplates 51 variables. In the year 2001, the publication of environmental indicators is extended, raising to 10 the number of indicators subject to analysis (OECD, 2001). The most comprehensive compendium is carried out by the OECD in 2002 in a very systematized manner, distinguishing three categories: social, with 6 indicators and 18 variables, economic (5 indicators and 22 variables) and environmental in which 7 indicators and 26 variables are presented. It initially adopts a Pressure - State - Response (PSR) model, adjusted to the specifications of each sector. In any case, although it is an interesting contribution as far as the standardization of information is concerned, and as a result, of data sources, it does not present a comparative system that goes beyond the figures presented and neither of course does it advance in the classification of variables nor does it offer concrete sustainability measurement systems.

With regard to the United Nations, said organization, through its Sustainable Development Committee, presented in 1993 a proposal for the selection of sustainability indicators which, after multiple and enormous papers - fundamentally based on the contributions of Moldan, et al (1997) - and various sessions and trials, concluded in 1999 with its practically definitive publication (UN, 1999). Methodologically it represents an advance with respect to those of the OECD as it presents four perfectly defined sustainability dimensions (economic, environmental, institutional and social), as well as the relation of said indicators with Agenda 21 and its insertion within the PSR framework. It defines 5 indicators in the economic sphere, 7 in the environmental, 4 in the institutional and 6 in the social dimension. It is summarized in a list of 59 variables and, as in the case of the OECD, it does not establish synthetic sustainability measurements nor comparisons between the indicators, limiting itself, as was previously indicated, to a very elaborate and comprehensive methodological approximation.

The European Union (EU), for its part, using the previously mentioned UN contributions as its base, elaborated a first approximation to global sustainability measurements in 1998, which it presented at the Goteberg Summit and which culminated in the year 2001 with the publication of the last proposal (Eurostat, 2001A). It presents a similar structure to that of the $\mathrm{UN}$ as it is based on identical dimensions or facets of sustainable development, although these are divided in turn into themes and sub-themes. 22 social, 16 environmental, 21 economic and 4 institutional indicators are used. The nature of the indicator within the framework of the PSR principles is not clearly defined, nevertheless equivalences are established between the indicators that it proposes and, where appropriate, the corresponding indicators of the UN and the OECD. As is the case of the other organizations that have previously been referred to, it does not provide a method of elaboration of global synthetic indexes which permit immediate comparisons from country to country.

It should be noted that the aforesaid official contributions only allow for very partial comparisons - from variable to variable or indicator to indicator - as they do not establish a homogeneous, synthetic and global manner in which to carry out the aforementioned comparisons. Nevertheless, they are the most immediate precedents of this new generation of sustainable development measurements, which are still in their early phase. In this sense, it is fundamental to highlight the contribution made to the World Economic Forum (WEF) by the Universities of Yale and Columbia, who have designed the Environmental Sustainability Index (ESI). This global synthetic indicator was initially presented in 2001 at the Davos G-8 Summit and revised and updated the following year (WEF, 2002). It is applied to 142 countries and includes 5 dimensions (environmental systems, reducing stresses, reducing human vulnerability, social and institutional capacity and global stewardship), which 
in turn are composed of 20 indicators, and subdivided into 68 variables. Its novelty lies in its methodological contribution and that it permits one sole synthetic indicator to be created for each country, which facilitates comparisons and decision making. On the contrary, its major weakness is probably its excessive geographical amplitude (142 countries), which makes it necessary to apply estimated values for many variables, with the subsequent distortion of the final synthetic results. On the other hand, as was previously stated, the ESI does not respond to the standardized sustainability classification in its components (as is the case of those proposed by the UN and EUROSTAT), nor does it relate the indicators with the Pressure - State - Response (PSR) principles nor with the local Agenda 21.

As can be observed from the preceding analysis, at present there is no methodological and calculation proposal that deals with all the facets of sustainable development in a complete manner, thus an adaptation and reformulation of said proposals is necessary for their subsequent practical application in order to carry out a comparison of different economies and specifically for regional analysis.

\section{Global synthetic index proposal}

With this background, we shall proceed to design a new global synthetic indicator that fulfils all the conditions that the aforementioned official approximations seek to approach and that presents a method of analysis that, even within its complexity, can be applied to different spheres. Lastly, it should be constructed on the basis of a methodology that has been duly tested and that has possibilities for development. In conclusion, it would be based on the following premises:

(1) It is essential that the index responds to the four generally accepted facets of sustainability: economic, social, environmental and institutional.

(2) Each of the variables should be classified under the scheme or model generally adopted by international organizations (OECD, UN \& Eurostat) Pressure - State - Response (PSR) or its variant DSR (Driving Force State - Response). The process is not complex if a concrete and previously defined methodology is adopted. In this case, DSR is chosen (Moldan, et al., 1997).

(3) Likewise, each variable should adapt to the specific principles of sustainability contained in each chapter of Agenda 21 and, as a result, fit in with said principles.

(4) The generated synthetic index, as well as the indicators, sub-indicators and variables on which it is based, must likewise adapt to certain principles (Bermejo, 2001, p. 270; Kane, 1999; Anderson, 1991, p. 49-51) amongst others:

a. They should be suitable in order to measure sustainability and its laws, showing the effects on the environment of the main human activities, and reflect reality and its changes with precision.

b. Applicable on a local, regional, national and global scale.

c. Suitable to its audience, depending on who is going to receive the information.

d. Applicable to specific locations, in such a manner that citizens can participate in sustainability policies that affect their welfare and that can be of use in decision-making.

e. Adequately allow for comparisons to be made.

(5) Under the aforementioned presuppositions, a so-called Synthetic Index of Sustainable Development (SISD) is formulated and defined, being structured in a pyramidal form; in this manner the synthetic index is composed, in turn, of four components or dimensions, which are divided into different indicators. These originate 
from the calculation of a certain number of sub-indicators, each one of them composed of a series of variables. Lastly, from a methodological perspective, its calculations are based on the contrasted analysis carried out by the Universities of Yale and Columbia (WEF, 2002) with a series of diverse modifications and adaptations that will be subsequently mentioned.

\section{Application of the SISD to the region of Galicia and to the European Union}

Having designed the synthetic index of sustainability, it is applied to the Galician reality and to the countries within the European Union, with the objective of ascertaining the position of this community and especially of its economic, social, environmental and institutional system within the European context and determining if it is run and governed within the framework of sustainable development, while simultaneously ranking and comparing it to the Spanish economy and to the remaining European areas.

When trying to apply empirical testing to the Galician region, the first issue to be taken into account is the availability of adequate and comparable statistical data in order to reach the projected objectives with reasonable results. In this aspect, it should be pointed out, that any reference or possibility of analyzing material flows of resources has been avoided not only because of the impossibility of obtaining the aforesaid within the Galician context, but also because it is impossible in all other ambits. Consequently, as is the case generally speaking, the application of measurements based on criteria of very strong sustainability is impossible. Secondly, the process used in order to determine the value of the variables that could be obtained for Galicia is based on a system of exclusion: given that official statistics for EU countries regarding sustainability are particularly recent and have been duly contrasted (especially Eurostat, 2001A and 2001B), as well as those of the World Bank, a wide array of variables were expressly selected from said sources. From this point onwards, with the aid of almost all statistical sources available for Galicia, those variables that originated from, in the majority of cases, direct sources that proved to be reliable and comparable, both from a methodological and temporal perspective, were gathered, thus avoiding unnecessary lags.

Through the aforementioned process, it was possible to select a total of 78 variables. Using these variables as a base, the complex steps towards obtaining sub-indicators, indicators, components and the index of sustainable development were established in accordance with the methodology and calculations that are developed below.

\section{Methodology}

Using the 78 selected variables as a starting point, these were grouped into 36 sub indicators, which in turn were concentrated into 13 indicators. Lastly, the indicators grouped in such a manner were distributed into the four known dimensions of sustainability to be subsequently analyzed: economic, institutional, environmental and social, which, in turn, compose the SISD. Such a level of breakdown and procedure was considered of an essential nature in order to carry out subsequent analysis, especially to contrast the attained sustainability measurements and the traditional measures of economic growth. Likewise, each of the variables was classified within the D-S-R model as well as its position in each of the Agenda 21 chapters. Table 1 includes the tabulation of the classification and the groupings established. 
Regional analysis and sustainable development: Application of a synthetic sustainability indicator to Galicia and the European Union

Table 1 Composition of the SISD: Dimensions, indicators, sub-indicators and number of variables

\begin{tabular}{|c|c|c|c|}
\hline Dimension & Indicator & Sub-indicator & Number of variables \\
\hline \multirow{13}{*}{ Economic } & \multirow{4}{*}{ Economic structure } & Economic performance & 4 \\
\hline & & Trade & 2 \\
\hline & & Financial status & 2 \\
\hline & & Combination of business & 2 \\
\hline & \multirow{9}{*}{ Consumption and production patterns } & Energy use & 2 \\
\hline & & Generation and disposal of municipal waste & 1 \\
\hline & & Generation of industrial waste & 1 \\
\hline & & Generation and disposal of hazardous waste & 1 \\
\hline & & Recycling of waste & 2 \\
\hline & & Passenger transport by mode & 1 \\
\hline & & Freight transport by mode & 1 \\
\hline & & Vehicles & 1 \\
\hline & & Environmental protection expenditures & 1 \\
\hline \multirow{5}{*}{ Institutional } & \multirow{5}{*}{ Institutional capacity } & Internet access & 1 \\
\hline & & Communication infrastructure & 2 \\
\hline & & Expenditure on research and development & 1 \\
\hline & & Risks to natural capital & 1 \\
\hline & & Risks to human capital & 1 \\
\hline \multirow{7}{*}{ Environmental } & Atmosphere & Air quality and climate change & 8 \\
\hline & \multirow{3}{*}{ Land } & Agriculture & 6 \\
\hline & & Forests & 3 \\
\hline & & Urbanization & 1 \\
\hline & \multirow{2}{*}{ Fresh water } & Water quantity & 1 \\
\hline & & Water quality & 2 \\
\hline & Biodiversity & Species and ecosystem & 2 \\
\hline \multirow{11}{*}{ Social } & \multirow{2}{*}{ Equity } & Poverty & 6 \\
\hline & & Gender equality & 2 \\
\hline & \multirow{3}{*}{ Health } & Illness & 6 \\
\hline & & Mortality & 3 \\
\hline & & Sanitation & 2 \\
\hline & \multirow{2}{*}{ Education } & Education level & 1 \\
\hline & & Literacy & 1 \\
\hline & Housing & Living conditions & 2 \\
\hline & \multirow{2}{*}{ Security } & Crimes & 1 \\
\hline & & Traffic accidents & 1 \\
\hline & Population & Population change & 3 \\
\hline
\end{tabular}

With the aim of carrying out a first approximation within the reach of the content of the proposed measurement system, in Table 2 said proposed system is compared with the contributions made by the different organizations that have already been thoroughly analyzed. Aside from quantifying the number of variables dealt with and verifying whether they cover all the dimensions of sustainability, reference is made as to whether a synthetic index is created in these contributions, whether they follow a P-S-R model and whether the variables are classified in accordance with the chapters and the objectives of Agenda 21. As may be observed, none of them cover all those aspects in an extensive manner. On the contrary, the SISD proposal analyses the greatest number of variables (78) out of all of them and is the only one that strictly complies with the last three requirements stated 
above.

Once the variables have been selected, the methodology, which is used to carry out all the calculation operations, is composed of the following stages:

(1) The first calculation phase is carried out on the basis of the different values observed and obtained for each one of the 78 variables for the 16 economies at issue (European Union and Galicia).

(2) Secondly, Z-scores are calculated, that is, the values of the variable, duly standardized, with the purpose of making them comparable. The calculation may be obtained in two different manners:

$Z s_{\mathrm{i}}=\frac{X i-\bar{X}}{\sigma x}$, if sustainability is direct, or

$Z s_{\mathrm{i}}=\frac{\bar{X}-X i}{\sigma X}$, if it is inverse. Where:

$Z s_{\mathrm{i}}=$ Value of the standardized variable.

$\bar{X}=$ Mean of distribution.

$X i=$ Value reached by the variable.

$\sigma x=$ Standard deviation of distribution.

(3) Subsequently, the values of the percentiles 97.5 and 2.5 are calculated, which are used in order to avoid that the extreme values distort the calculations. In this manner, and in a latter process, the maximum and minimum values are substituted by the value of the respective percentiles ( 97.5 and 2.5). Although this process is typical of ample distributions (WEF, 2002, p. 46), which is not the case under question, with said process the values of invalid variables are corrected (in the event that they were unknown or not available or if they were excessively dispersed).

Table 2 Comparison of the selections of indicators and variables according to the different organizations and the SISD proposal

\begin{tabular}{|c|c|c|c|c|c|c|c|c|c|c|}
\hline \multirow{3}{*}{ Dimension } & \multicolumn{10}{|c|}{ Organization/Proposal } \\
\hline & \multicolumn{2}{|c|}{ OECD (2002) } & \multicolumn{2}{|c|}{ UN (1999) } & \multicolumn{2}{|c|}{ Eurostat (2001a) } & \multicolumn{2}{|c|}{ WEF (2002) } & \multicolumn{2}{|l|}{ SISD } \\
\hline & Variables & $\mathrm{N}^{\mathrm{o}}$ & Variables & $\mathrm{N}^{\mathrm{o}}$ & Variables & $\mathrm{N}^{\mathrm{o}}$ & Variables* & $\mathrm{N}^{\mathrm{o}}$ & Variables & $\mathrm{N}^{\mathrm{o}}$ \\
\hline Social & $\bullet$ & 18 & $\bullet$ & 20 & $\bullet$ & 22 & & - & $\bullet$ & 28 \\
\hline Environmental & $\bullet$ & 26 & $\bullet$ & 19 & $\bullet$ & 16 & & - & $\bullet$ & 23 \\
\hline Economic & $\bullet$ & 22 & $\bullet$ & 14 & $\bullet$ & 21 & & - & $\bullet$ & 21 \\
\hline Institutional & & - & $\bullet$ & 6 & $\bullet$ & 4 & & - & $\bullet$ & 6 \\
\hline Number of variables & & 66 & & 59 & & 63 & & 68 & & 78 \\
\hline Synthetic index & \multicolumn{2}{|l|}{ No } & \multicolumn{2}{|l|}{ No } & \multicolumn{2}{|l|}{ No } & \multicolumn{2}{|l|}{ Yes } & \multicolumn{2}{|l|}{ Yes } \\
\hline P-s-r scheme & \multicolumn{2}{|l|}{ Yes } & \multicolumn{2}{|l|}{ Yes } & \multicolumn{2}{|l|}{ No } & \multicolumn{2}{|l|}{ No } & \multicolumn{2}{|l|}{ Yes } \\
\hline Relation with ag.21 & \multicolumn{2}{|l|}{ No } & \multicolumn{2}{|l|}{ Yes } & \multicolumn{2}{|l|}{ Yes } & \multicolumn{2}{|l|}{ No } & \multicolumn{2}{|l|}{ Yes } \\
\hline
\end{tabular}

Note: $\bullet$ Covered dimension.

* The WEF methodology (2002) classifies the dimensions in: environmental systems, reducing stresses, reducing human vulnerability, social and institutional capacity and global stewardship.

(4) Once all and each one of the calculations of the 78 variables taken into account for the 16 economies have been generated, it is necessary to continue with the latter process of calculating indicators, which complies with the following guidelines:

a. The value of the standardized variable is corrected for the values reached by the percentiles 97.5 and 2.5 , 
Regional analysis and sustainable development: Application of a synthetic sustainability indicator to Galicia and the European Union

with the aim of avoiding - as has previously been stated - an ample dispersion in the values of the variable.

b. The value of the standardized variable of each indicator is obtained by calculating the simple average of the variables' $z$-scores, classified according to the sub-indicators in which each of the former are composed (WEF, 2002, p. 46). The results obtained are presented in Table 3.

Table 3 Values of the indicators (z-scores)

\begin{tabular}{|c|c|c|c|c|c|c|c|c|c|c|c|c|c|}
\hline & \multicolumn{2}{|c|}{ Economic } & \multirow{2}{*}{\begin{tabular}{|c|} 
Institutional \\
Institutional \\
capacity
\end{tabular}} & \multicolumn{4}{|c|}{ Environmental } & \multicolumn{6}{|c|}{ Social } \\
\hline & $\begin{array}{l}\text { Economic } \\
\text { structure }\end{array}$ & $\begin{array}{l}\text { Consumption } \\
\text { and } \\
\text { production } \\
\text { patterns }\end{array}$ & & Atmosphere & Land & $\begin{array}{l}\text { Fresh } \\
\text { water }\end{array}$ & Biodiversity & Equity & Health & Education & Housing & Security & Population \\
\hline Austria & -0.04 & 0.42 & 0.16 & 0.51 & 0.48 & 0.70 & 0.38 & 0.61 & 0.15 & 0.89 & -0.41 & 0.18 & 0.15 \\
\hline Belgium & -0.27 & 0.02 & -0.01 & 0.14 & -0.78 & -1.57 & -0.20 & 0.01 & -0.16 & -0.13 & 0.62 & 0.50 & -0.58 \\
\hline Denmark & 0.73 & 0.44 & 0.80 & -0.65 & -0.37 & 0.71 & 1.89 & 0.95 & -0.47 & 1.18 & -0.01 & 0.30 & -0.03 \\
\hline Finland & 0.19 & -0.01 & 0.97 & -0.09 & 0.61 & -0.14 & 0.16 & 0.29 & 0.30 & 0.69 & -0.28 & -0.34 & 0.21 \\
\hline France & 0.07 & -0.27 & 0.15 & 0.00 & -0.76 & 0.01 & -0.93 & -0.14 & 0.23 & 0.08 & 0.45 & 0.11 & -0.12 \\
\hline Galicia & -0.53 & -0.09 & -1.70 & -0.46 & 0.33 & 0.28 & -1.17 & -1.32 & -0.85 & -1.02 & 0.71 & 0.05 & 0.39 \\
\hline Germany & -0.10 & -0.51 & 0.24 & 0.61 & -0.22 & -0.24 & -0.81 & 0.38 & -0.02 & 1.18 & -0.48 & 0.08 & 0.07 \\
\hline Greece & -0.43 & 0.39 & -1.12 & -0.09 & -0.08 & -0.51 & 0.33 & -0.76 & 0.58 & -0.56 & -0.85 & 0.27 & 0.42 \\
\hline Ireland & 0.30 & -0.11 & -0.64 & -0.87 & -0.10 & 0.35 & -0.95 & -0.21 & -0.75 & -0.62 & 0.74 & -0.80 & 0.04 \\
\hline Italy & -0.55 & 0.02 & -0.20 & 0.47 & 0.06 & -0.61 & 0.04 & -0.26 & 0.43 & -0.94 & -0.52 & -0.54 & -0.01 \\
\hline Luxembourg & 0.47 & -0.64 & 0.44 & -0.77 & 0.65 & 0.30 & 0.00 & 0.33 & 0.20 & 0.13 & 0.92 & 0.37 & 0.23 \\
\hline Netherlands & 0.47 & 0.05 & 0.60 & 0.25 & -0.67 & 1.04 & 1.55 & 0.53 & -0.12 & 0.31 & 0.66 & -0.33 & -1.02 \\
\hline Portugal & -0.68 & 0.38 & -0.58 & 0.12 & 0.12 & -0.63 & 0.19 & -0.52 & -0.49 & -1.94 & -0.48 & 0.45 & 0.01 \\
\hline Spain & -0.38 & -0.04 & -0.62 & 0.24 & -0.12 & -1.25 & 0.35 & -0.58 & 0.32 & -1.43 & -0.74 & -0.49 & 0.17 \\
\hline Sweden & 0.74 & 0.18 & 1.34 & 0.26 & 0.99 & 1.08 & -0.16 & 0.77 & 0.94 & 1.00 & -0.31 & 0.28 & 0.46 \\
\hline $\begin{array}{l}\text { United } \\
\text { kingdom }\end{array}$ & 0.01 & -0.22 & 0.18 & 0.32 & -0.15 & 0.48 & -0.67 & -0.07 & -0.30 & 1.18 & -0.02 & -0.10 & -0.39 \\
\hline
\end{tabular}

Table 4 Values reached by dimensions and SISD

\begin{tabular}{|c|c|c|c|c|c|}
\hline & Economic & Institutional & Environmental & Social & SISD \\
\hline Austria & 70.6 & 53.0 & 85.0 & 63.7 & 71.0 \\
\hline Belgium & 47.1 & 40.0 & 21.3 & 44.0 & 37.8 \\
\hline Denmark & 96.7 & 86.0 & 33.1 & 55.4 & 62.3 \\
\hline Finland & 55.5 & 93.0 & 59.3 & 63.1 & 62.2 \\
\hline France & 35.4 & 46.0 & 23.7 & 51.3 & 38.4 \\
\hline Galicia & 23.5 & 0.0 & 45.6 & 19.1 & 26.6 \\
\hline Germany & 22.2 & 66.0 & 52.1 & 55.9 & 46.5 \\
\hline Greece & 54.6 & 6.0 & 41.8 & 55.3 & 47.3 \\
\hline Ireland & 48.4 & 11.0 & 29.1 & 25.2 & 31.5 \\
\hline Italy & 30.6 & 33.0 & 63.2 & 47.5 & 46.5 \\
\hline Luxembourg & 41.0 & 73.0 & 54.3 & 68.1 & 57.1 \\
\hline Netherlands & 72.7 & 80.0 & 48.8 & 50.4 & 58.2 \\
\hline Portugal & 41.9 & 26.0 & 52.1 & 23.2 & 37.0 \\
\hline Spain & 33.3 & 20.0 & 46.0 & 44.0 & 39.9 \\
\hline Sweden & 85.9 & 100.0 & 85.4 & 90.4 & 88.4 \\
\hline United Kingdom & 35.7 & 60.0 & 54.0 & 37.0 & 43.4 \\
\hline
\end{tabular}


(5) The next and final phase of the process entails:

a. The transformation of the values of the standardized variable, as obtained in the previous phase, in such a manner that they can be understood and compared. For said purpose, the z-score of each indicator is converted into the normal standard percentile, with a theoretical value between 0 and 100 .

b. Obtaining the values of the percentiles of each SISD component or dimension (economic, institutional, environmental and social) through the weighted average of the percentiles calculated for the indicators.

c. Lastly, the value of the SISD index is obtained through the weighting of the average of the percentiles calculated for each one of the dimensions or components of the index. The results obtained are presented in Table 4 .

\section{Coherency tests}

In order to establish whether the results obtained are significant and coherent, it is necessary to ascertain if the values of the percentiles calculated for the four dimensions of the index and for the SISD are representative of a normal distribution. For the aforementioned purpose the statistical programme SPSS was used and specifically the calculations were carried out on Box - plot. Once the calculations have been carried out for the values reached in the four indexes of sustainability for the considered dimensions or facets and for the SISD, the results obtained prove the coherency, the goodness and the representative nature of said indexes for the institutional, environmental and economic dimensions, given that no isolated or extreme value exists. Accordingly, the aforementioned calculations of the percentiles are coherent and of a representative nature, thus it is possible to analyze the results obtained with a total guarantee of reliability.

\section{Results}

\subsection{SISD, components and indicators}

The most outstanding issues in each country and region are analyzed below.

Austria. - It occupies the second position in the Synthetic Index of Sustainable Development in relation to the rest of the EU and Galicia $(71,0)$. The only relative disequilibrium is to be found in the institutional sphere, and the lower values of the social component are due, without doubt, to the housing variable, that presents unfavorable figures. It is foreseeable that institutional actions will be propitiated by the government (2001), said actions which are designed to reach medium-term objectives, have an influence on the role of national, federal, provincial and local authorities as promoters of coordinated strategies which facilitate sustainable development.

Belgium. - With a 37, 8 SISD it occupies the 13th position out of the 16 economies analyzed. It presents low values in its social, economic and institutional dimensions and very low values in the environmental sphere, where water and land register very meagre values in the standardized variable. Government plans (2000), which define the strategies for sustainability, have commenced with the start up of the Federal Council of Sustainable Development, which furthermore foresees, aside from the implementation of strategies, the participation of all of society.

Denmark. - Ranked in third place of the SISD $(62,3)$ it presents nonetheless certain disequilibrium. Whereas in the institutional and economic sphere it attains excellent values (86.0 and 96.7, respectively), the social component is relatively lower (the value of the health indicator affects the aforesaid social component) and the fairly negative values of land and atmosphere create an imbalance in the environmental component (33.1).

Finland. - With a value of 62.2 in the SISD, it occupies the third position in the ranking of the economies 
under examination. The social, environmental and economic aspects (63.1, 59.3 and 55.5, respectively) are relatively balanced, although in the social facet the housing and security indicators are low. The enormous concern for sustainability within the institutional sphere (93.0) powerfully draws ones attention, said concern no doubt being the expression of or is related to a governmental strategy for very developed sustainability (2000). In effect, the decision of the State Council which puts it into practice takes the form of a document of ample and systematic content which defines the courses of action and the strategic sectorial objectives (international cooperation, production and consumption, energy, regional and urban structure, transport, rural areas and use of renewable resources, research and education) and the ways of implementing the programmes and controlling and ensuring objectives.

France. - With a 38.4 index, it is located in the $12^{\text {th }}$ position of the ranking established of the 16 areas object of analysis. It presents one of the lowest indexes in the environmental facet (23.7) - no doubt due to the very meagre values of the land indicators and especially, biodiversity - followed by the economic sphere (35.4), resulting from the low levels of sustainable consumption and production, and the social (51.3). The process of design by the government of official strategies for sustainable development (2001) is at a very backward stage. The commission, whose function it is to prepare the Environmental Charter, which should hopefully be drawn up in a one-year period, was only set up as late as June 2002.

Galicia. - It is the last of the areas dealt with in the evaluation of sustainability carried out through the SISD. It reaches a value of 26.6. In terms of components, the institutional capacity for sustainability presents the worst value of all the economies analyzed (0.0). The social dimension (19.1) is very low, predominantly as a result of the low or very low values of the equity, health and educational indicators. As far as the economic dimension is concerned, its low evaluation (23.5) is especially a consequence of the low percentage attained by the economic structure indicator, and to a lesser extent, to that attained by consumption and production. Lastly, environmental sustainability is the dimension that obtained a relatively better value (45.5), where the positive values of the water and land indicators compensate the negative figures obtained for atmospheric pollution and biodiversity protection.

Germany. - It presents an intermediate value in the SIDS (46.5) and is eighth in the ranking of countries/ economies. The institutional dimension presents the greatest value (66.0), followed by the social (55.9) and the environmental (52.1), even though biodiversity, water and land are relatively low indicators. Economic sustainability is very scarce (consumption and production and economic structure present low indexes), due without doubt to the unification process and that many of the analyzed variables are defined in per capita terms. Despite the fact that the German Government (2000) has tried to put a sustainability strategy into place, the main weakness of the German policies in this respect, (aside from the difficulties which have followed as a result of the aforementioned reunification) is to be found in the state's federal structure and in its distribution of powers which - in many cases due to political differences - totally impedes essential and multi-level coordination (Jänicke, et al., 2001, p. 28), from which follows the slowness of the process of implementation of a global strategy.

Greece. - Oddly enough, and despite what one could think, it occupies the seventh position in the ranking of the areas under analysis (SISD 47.3). It presents a practically non-existent institutional capacity for sustainability (6.0). In the environmental sphere it obtains an average value (41.8), consequence of the low index in water, which is duly compensated with a positive protection of biodiversity. The economic dimension attains 54.6 but is unbalanced due to the fact that sustainable methods of consumption and production coexist with an economic structure with a low index of sustainability. Lastly, in the social dimension (54.8), very low values corresponding 
to the housing, education and equity variables coexist with acceptable percentages of population, security and health.

Ireland. - The country which has grown the most within the EU in the last years, in terms of traditional methods of measurement, is also the country that presents the worst index of sustainability of all the states within the Union (31.5) and is accordingly placed in the last position of the ranking. In the environmental dimension (29.1), it presents a worrying situation as far as biodiversity and atmosphere are concerned, and in the social dimension (25.2) the security, education and health indicators are particularly low. The economic component (48.4) proves to be balanced with positive economic structure indicators and relatively low indexes of sustainability with reference to consumption and production. Finally, the institutional dimension (11.0) is very low, which is reflected in a fairly meagre index of capacity for this dimension.

Italy. - It occupies the ninth position in the ranking of countries under consideration (a SISD of 46.5). The economic dimension is especially low (30.6, with a low structure indicator and an intermediate one for sustainable consumption and production). From an environmental perspective it presents an acceptable index (63.2) and in the social dimension it reaches an intermediate value (47.5), in the latter the education indicator and especially the security and housing indicator, and to a lesser extent that of equity are quite low. The institutional position is also quite meagre (33.0).

Luxembourg. - With a SISD of 57.1, it occupies the sixth position and it presents ample institutional and social dimensions (73.0 and 68.1, respectively). Its extremely low position with reference to the indicator for pollution and contribution to the green house effect, affects the environmental function (54.3) and, finally, the economic dimension presents the lowest index of them all (41.0), due to the low indicator of sustainable consumption and production.

Netherlands. - It is located in $5^{\text {th }}$ position with a value of 58.2 in the SISD. It attains most acceptable values in the institutional (80.0) and economic (72.7) dimensions. These values are lower in the social (50.4 in which population and security offer the lowest values of the respective indicators) and the environmental dimensions (48.4) in which the sustainable use of its land is its worse reference.

Portugal. - It presents a general situation of unsustainability with a SISD of 37.0 and occupies the $14^{\text {th }}$ position of the economies that have been dealt with. Especially low is the social component (23.2 in which the education indicator is particularly negative, followed by low values in housing, health and equity) and the institutional (26.0). The indexes of the economic components are of a modest nature (41.9) as a result of the negative economic structure indicator, as well as that pertaining to environmental sustainability, in which the water indicator offers a significantly low value.

Spain. - The Spanish economy occupies the $11^{\text {th }}$ position out of the total of economies that have been examined (SISD 39.9). The low ranking order of the institutional component stands out, said low ranking being the result of the scarce official capacity for sustained development that is endorsed by this indicator. The social component is also low (44.0) as a result of the negative values of the security, housing, education and equity indicators. The equally low values of the economic structure and production indicators condition a meagre index of the economic component (33.3) and in the environmental sphere, in which the index reaches a value of 46.0, the water indicator weighs exceedingly on said index.

Sweden. - It represents the maximum level $\left(1^{\text {st }}\right)$ in the ranking of sustained development of the economies that have been subject to analysis (SISD 88.41) and is an example of balanced sustainability. In effect, it reaches the maximum value in the sphere of institutional capacity (100.00) and 90.4 with reference to the social 
component in which all the values of the indicators are positive, with the exception of housing. The methods of sustainable production and consumption and of economic structure lead to an index of economic sustainability of 85.9. Lastly, in environmental sustainability it obtains a value of 85.4 , with all the values of the indicators that compose said dimension adopting positive values, with the slight exception of protection of the biodiversity. These figures are endorsed if one analyses the governments' actions (1999), which most certainly serve as a model. This can be appreciated by merely looking over, for example, the last governmental strategies for sustainability (2001). Amongst its principles the following stands out:

"Sweden is one of the countries that developed various sustainability philosophies as early as the end of the 19th century. The Swedish sustainable development strategy is based on a democratic system of government and the values this implies. Democracy makes it possible to make rules and build institutions that promote resource-efficient consumption and production patterns and defend the public goods - knowledge, health and the environment - on which a sustainable and progressive development of society is based." (Government of Sweden, 2001, p. 8).

Having implemented the strategy on all geographical levels (global, national and local, with reference to the latter $70 \%$ of all municipalities have adhered to the Aalborg Charter) and having obtained the active participation of civil society, from 1998 until 2003, 2300 million euros will be applied to local projects that are committed to sustainable development exclusively from an environmental perspective, with the state government contributing at least to $30 \%$ of their cost of implementation.

The results attained by Sweden in the SISD are the unequivocal result of a democratic and participative culture, with a consequent historical commitment to the values of sustainability, and the public authorities' resolute backing of the aforementioned values both in the design of their policies and in the assignment of funds in order to obtain the proposed objectives.

United Kingdom. - It occupies the $10^{\text {th }}$ position in the ranking (43.4), nevertheless special emphasis should be placed on its balanced nature. The institutional dimension stands out (60.0) above the rest. The lack of protection of the biodiversity is compensated with the favourable water and atmosphere indicators, the end result being that the environmental dimension presents an index of 54.0. The economic component (35.7) is low, as a consequence of a consumption and production indicator that is not very compatible with sustained development, as is the social dimension (37.0), in which the greater value of the education indicator is not capable of surmounting the low population and equity indexes. In line with the results obtained, the strategic plans for sustainable development of the British government (2000) place utmost importance in attaining a better standard of living and establish four objectives: social progress (which acknowledges the needs of everyone), effective protection of the environment, careful use of natural resources and the maintenance of high or stable levels of economic growth and employment.

\subsection{Sustainable development and economic growth}

Reference was previously made to the debate between the traditional methods of measuring development, articulated through GDP, and the need for new indicators or accounting systems that measure the levels of sustainability. The empirical analysis carried out, allows for statistical comparisons to be made between the SISD values, its dimensions and the indicators that constitute each one of them, and GDP per capita of each economy and its variations in the last years.

The procedure turns out to be quite simple and to that effect the values obtained in the exposed empirical assumption are compared with the GDP figures per capita in the European Union (Eurostat, 2001A) and Galicia 
Regional analysis and sustainable development: Application of a synthetic sustainability indicator to Galicia and the European Union

(INE, 2001A) and the variations of the same at constant prices from 1990 to 2000. In this manner it is possible to analyze if a direct or inverse relation exists between sustainability and GDP in static form (through the current value of the same) or dynamic form (dependent on GDP's fluctuations).

Two systems have been selected in order to compare said variables: through a linear correlation coefficient and Spearman correlation. Given that the mathematical formulas of both coefficients are extensively known, they are not herein exposed. The values obtained are included in Table 5.

In the first place, the correlation between the values of the SISD and GDP are very low (0.299 linear and 0.268 corresponding to rank correlation). If we relate the synthetic index with the variations in GDP in the last ten years we obtain an inverse relation (-0.484 linear and -0.344 rank correlation). It can be deduced that, in principle, sustainability and GDP do not have a relation, but quite to the contrary: as GDP increases, the level of sustainable development decreases.

Table 5 Correlation coefficients between dimensions, indicators, SISD and GDP per capita (2000) and variations in GDP (1990-2000)

\begin{tabular}{|c|c|c|c|c|}
\hline & \multicolumn{2}{|c|}{ Linear correlation } & \multicolumn{2}{|c|}{ Spearman correlation } \\
\hline Dimensions, indicators and SISD & $\begin{array}{l}\text { In relation to } \\
\text { GDP per capita }\end{array}$ & $\begin{array}{l}\text { In relation to the } \\
\text { variations in GDP }\end{array}$ & $\begin{array}{l}\text { In relation to } \\
\text { GDP per capita }\end{array}$ & $\begin{array}{l}\text { In relation to the } \\
\text { variations in GDP }\end{array}$ \\
\hline Economic & 0.166 & -0.124 & 0.350 & 0.126 \\
\hline Economic structure & 0.667 & -0.031 & 0.718 & -0.006 \\
\hline Consumption and production patterns & -0.537 & -0.436 & -0.185 & 0.068 \\
\hline Institutional & 0.503 & -0.547 & 0.450 & -0.406 \\
\hline Institutional capacity & 0.542 & -0.557 & 0.450 & -0.406 \\
\hline Environmental & 0.011 & -0.318 & -0.115 & -0.350 \\
\hline Atmosphere & -0.372 & -0.704 & -0.271 & -0.753 \\
\hline Land & 0.117 & 0.070 & -0.138 & 0.159 \\
\hline Fresh water & 0.340 & 0.142 & 0.447 & 0.059 \\
\hline Biodiversity & 0.039 & -0.309 & -0.015 & 0.115 \\
\hline Social & 0.388 & -0.607 & 0.391 & -0.397 \\
\hline Equity & 0.599 & -0.442 & 0.641 & -0.309 \\
\hline Health & 0.445 & -0.662 & -0.191 & -0.562 \\
\hline Education & 0.445 & -0.408 & 0.438 & -0.485 \\
\hline Housing & -0.029 & 0.496 & 0.665 & 0.424 \\
\hline Security & -0.154 & -0.379 & 0.097 & 0.006 \\
\hline Population & -0.154 & 0.163 & -0.274 & 0.138 \\
\hline SISD & 0.299 & -0.484 & 0.268 & -0.344 \\
\hline
\end{tabular}

The preceding affirmation is only confirmed upon a deeper analysis of the SISD dimensions and indicators. These particularities are subsequently analyzed.

The economic dimension, which in theory should experiment a similar behaviour to GDP and its variations, records practically non-existent or very low interrelation coefficients in all its components, with the exception of the linear correlation with GDP variations, which is inverse. Out of the indicators included in this category, only those referring to economic structure reach high values, those that relate the indicator with GDP per capita linearly or by rank. The sustainable consumption and production patterns present an inverse or practically non-existent correlation with respect to growth (measured in traditional terms).

As GDP increases the institutional dimension presents inverse values (which means that as the economy 
grows the state is concerned to a lesser degree with sustainable development) and scarce linear correlation with the static values of the same.

The environmental dimension presents inexistent or inverse correlation values. It is interesting to point out the debate which arose in the nineties - and which still remains open to the present day - regarding the application of Kuznets' Curves (initially conceived to relate inequality and GDP), to the environmental dimension, relating variations in wealth with the environment's degradation (especially atmospheric pollution). If the aforementioned assumption is fulfilled, in low rent situations, environmental degradation would increase up to a certain level. Having reached this level, as GDP increases, countries would start looking after environmental aspects more and thus degradation would decelerate. Kuznet's environmental curve would therefore adopt the form of an inverted U. Empirical verifications are, as previously stated, the object of profound controversies (Bermejo, 2001, p. 115). This methodology was recently applied to the Spanish economy (Roca et al., 2001). The conclusion of said application is that the environmental curve assumption is not fulfilled, with the exception of $\mathrm{SO}_{2}$ emissions. Said assertion confirms the conclusions of this article and more specifically with the atmosphere indicator in which all the correlation values reached are inverse.

Lastly, the social dimension presents a very scarce correlation (both lineal and by ranks) with regard to GDP per capita and inverse - in both categories - with regard to the variations of the same. This is the general behaviour of all the indicators included in this dimension of sustainability, with minimal exceptions in equity and housing in relation to GDP per capita (by ranks) and in the linear correlation of GDP with education, health and equity. Nevertheless, the aforementioned exceptions are not of a significant nature.

The analysis carried out does not permit one to affirm that high income levels or positive variations in said income are synonymous of sustainable development, rather the affirmation would be quite to the contrary. Both measurement systems lead to inverse results.

\section{Conclusions}

The different systems for measuring sustainable development, used up to the present date, have been analyzed in this Article. With the aforesaid background a synthetic global index has been designed. This index proves to be very useful and adequate in order to measure sustainability in different geographical areas, including on a regional basis. Using the designed methodology the synthetic index has been applied and used to compare the level of sustainable development in all the EU countries and the region of Galicia. The results obtained have passed the coherency tests that they have been subjected to. It is important to highlight Galicia's exceptionally low level of sustainability when compared with other European economies and particularly its practically non-existent institutional capacity for sustainable development, which is beyond doubt the consequence of the lack of medium to long term planning policies in this region. Geographically speaking, Europe's map of sustainability can be drawn from North - East to South - West. In this manner, northern and central European countries present the highest levels of sustainable development. As one moves towards the Atlantic and Mediterranean areas, said levels decrease. The highest indexes of sustainability are reached in those economies and countries whose respective governments have developed sustainable development strategies. On the other hand, it has been extensively proved that there is no relation whatsoever between traditional measurements of economic growth (GDP and its variations) and sustainability. 
Regional analysis and sustainable development: Application of a synthetic sustainability indicator to Galicia and the European Union

\section{References:}

Amerini, G. (2000). Social protection in Europe: Expenditure on pensions. Statistics in Focus, 3(6). Eurostat.

Anderson, V. (1991). Alternative economic indicators. London: Routledge.

Augas de Galicia. (2000). Plan de saneamento de Galicia 2000-2015. Documento de síntese. Retrieved from http/www.xunta.es.

Barclay, G., Tavares, C. \& Siidique, A. (2001). International comparisons of criminal justice statistics. United Kingdom: Home Office.

Behrens, A. (2001). Unemployment in the regions of the European Union 2000. Statistics in Focus, 1(7). Eurostat.

Bermejo, R. (2001). Economía sostenible: Principios, conceptos e instrumentos. Bilbao. Bakeaz.

Castañeda, B. (1999). An Index of Sustainable Economic Welfare (ISEW) for Chile. Ecological Economics, 28, 231-244.

CES GALICIA. (2000). Principais indicadores do peso da economía de Galicia no conxunto de España en 2.000. Retrieved from http://www.ces.es.

Daly, H. E. \& Cobb, J. B. (1989). For the common good. London: Green Print.

EUROSTAT. (2000). Health in the EU under the microscope. A first statistical guide. Collection News Releases, 103.

EUROSTAT. (2001A). Measuring progress towards a more sustainable Europe. Proposed indicators for sustainable development. Luxembourg. European Communities.

EUROSTAT. (2001B). Environment statistics. Luxembourg. European Communities.

EUROSTAT. (2002). Quality of work. Fatal accidents at work. Statistic. Retrieved from http://europa.eu.int/comm/eurostat.

Fundación La Caixa. (2001). Anuario social de España. Barcelona.

FUNGESMA. (2002). Medio ambiente en España. Anuario 2002. Madrid. Fungesma.

Gobierno de España. (2002). Estrategia Española de desarrollo sostenible. Retrieved from http://www.esp-sostenible.net.

Government of Austria. (2001). Austria's Strategy of sustainable development. Retrieved from http://www.cedar.at/data/nup/nup-engli.

Government of Belgium. (2000). Belgium's strategy of sustainable development. Retrieved from http://environment.fgov.be/Root/task/SD-DD/index.

Government of Finland. (2000). Finland's strategy of sustainable development. Retrieved from http://www.vyh.fi/eng/environ/sustdev.

Government of France. (2001). France's strategy of sustainable development. Retrieved from http://www.environnement.gouv.fr.

Government of Germany. (2000). Germany's strategy of sustainable development.

Government of Sweden. (1999). Sweden's national strategy of dustainable development. Retrieved from http://environ.se.

Government of Sweden. (2001). Sweden's national strategy of sustainable development. Stockholm. Ministry of the Environment. Danagärds Grafiska.

Government of United Kingdom. (2000). United Kingdom's strategy of sustainable development. Retrieved from http://www.environment. detrgov.uk/ sustainable .

Hansen J. (2001). Organic farmer. Statistics in Focus, 8(5). Luxembourg. Eurostat.

Hueting, R. \& Bosch, P. (1990). On the correction on National income for environmental losses. Statistical Journal of the United Nations 7, 75-83.

IGE. (1998). Datos Galicia 1998. Retrieved from http://.www.xunta.es/auto/ige.

IGE. (1999A). Datos Galicia 1999. Retrieved from http://xunta.es/auto/ige.

IGE. (1999B). Estatísticas do mercado de traballo. Anuario 1.999. Santiago de Compostela. Xunta de Galicia.

IGE. (1999C). Galicia en Cifras. Anuario 1999. Santiago de Compostela. Xunta de Galicia.

IGE. (2000A). Datos Galicia 2000. Retrieved from http://www.xunta.es/auto/ige.

IGE. (2000B). Enquisa sobre condicións de vida. Retrieved from http://www.xunta.es/auto/ige.

IGE. (2000C). Datos Pensións. Importe das prestacións económicas en 1998. Retrieved from http://www.xunta.es/auto/ige.

IGE. (2001A). Galicia en Cifras 2.000. Retrieved from http://www.xunta.es/auto.ige.

IGE. (2001B). Enquisa de condicions de vida. Retrieved from http:/www.xunta. es/auto/ ige.

IGE. (2002). Contas económicas de Galicia. Serie 1995 - 1999. Retrieved from http://www.xunta.es/auto/ige.

INE. (1998). Anuario estadístico de España. Madrid: Instituto Nacional de Estadística.

INE. (1999). INEDAT. Anuario estadístico 1999. Madrid: Instituto Nacional de Estadística.

INE. (2000). Encuesta sobre la recogida y tratamiento de residuos urbanos 2000. Retrieved from http://www.ine.es.

INE. (2001A). Contabilidad regional de España. Base 1.995. Retrieved from http://www.ine.es.

INE. (2001B). Encuesta sobre la generación de residuos en la industria 1999. Retrieved from http//:www.ine.es. 
INE. (2001C). Encuesta sobre el suministro y tratamiento del agua. Retrieved from http://ine.es.

INEGA. (2000). Libro blanco da Enerxía. Retrieved from http://www. xunta.es/auto/inega.

Jackson, T. \& Stymne, S. (1996). Sustainable economic welfare in Sweden. A Pilot Index 1950-1990. Stockholm Environmental Institute, New Economics Foundation.

Jänicke, M., Jörgens, H., Jörgensen, K. \& Nordbeck, R. (2001). Governance for sustainable development in Germany: Institutions and policy making. OECD. Retrieved from http://www.oecd.org.

Jímenez Herrero, L. M. (2000). Desarrollo sostenible: Transición hacia la coevaluación global. Madrid: Pirámide.

Kane, M. (1999). Sustainability concepts: From theory to practice. In: Sustainability in question. Massachusetts: Edward Elgar. $15-32$.

Lööf, A. \& Finn, N. (2001). Road-traffic deaths in the regions of Europe. Statistics in Focus, 1(5). Eurostat.

MAPYA. (2000). Anuario de estadística agroalimentaria 2000. Retrieved from http://www.mapya.es.

MAPYA. (2002). Hechos y cifras del sector agroalimentario y del medio rural español: Agricultura Ecológica. Madrid: Ministerio de Agricultura, Pesca y Alimentación.

Martinez-Alier, J. (1999). Introducción a la economía Ecológica. Barcelona: Rubes Editorial, S.L.

MCYT. (2002). Indicadores de ciencia y tecnología. Retrieved from http:www.mcyt.es.

MMA. (2001). Medio Ambiente en España 2000. Retrieved from http/:www.mma.es.

Moldan, B., Billharz, S. \& Matravers, R. (1997). Sustainability indicators: Report on project on indicators of sustainable development. Chichester: John Wiley.

Nordhaus, W. \& Tobin, J. (1972). Is economic growth obsolete?. Economic Growth, Fiftieth Anniversary Colloquium. New York: National Bureau of Economic Research.

OECD. (1998). Towards sustainable development: Environmental indicators. OECD.

OECD. (2001). Key environmental indicators. Retrieved from http/www.oecd.org.

Palacios, A. (2001). Análisis comparativo del gasto presupuestario en medio ambiente por todas las comunidades autónomas españolas. Zaragoza: Fundación Ecología y Desarrollo.

Proops, J.L.R., Atkinson, G., Von Schlotheim, B.R. \& Simon, S. (1999). International trade and the sustainability footprint: a practical criterion for its assessment. Ecological Economics, 28, 75-97.

Roca, J., Padilla, E. Farré, M. \& Galletto, V. (2001). Economic growth and atmospheric pollution in Spain: Discussing the environmental Kuznets curve hypothesis. Ecological Economics, 39, 85-99.

Serageldin, I. (1996A). Sustainability as opportunity and the problem of social capital. Brown Journal of World Affairs, 3(2), 187-203.

Serageldin, I. (1996B). Sustainability and the wealth of nations: Firs steps in an ongoing journey. Washington, D.C: World Bank.

SERGAS. (2000): Presupostos 2000. Retrieved from http://www.sergas.es.

UN. (1999). United Nations sustainable development: Indicators of sustainable development. Retrieved from http://www.un.org/esa/sustdev.

Wackernagel, M. \& Rees, W. E. (1996). Our ecological footprint: Reducing impact on the earth. Philadelphia: New Society Publishers.

WEF. (2002). World Economic Forum: 2002 environmental sustainable index. Retrieved from http://www.ciesin.columbia.edu/indicators/ESI.

WHO. (2000). World Health Organization and the United Nations Children's Fund. Global water supply and sanitation assessment 2000. New York: WHO and UNICEF.

World Bank. (2001). World development indicators 2001. Washington DC: World Bank.

Xunta de Galicia. (1985). Galicia en cifras. Anuario. Santiago de Compostela: Centro de Información Estadística.

Xunta de Galicia. (1999A). Anuario de Estadística Agraria (AEA). Retrieved from http:/www. xunta.es/conselle/ag.

Xunta de Galicia. (1999B). Macromagnitudes agrarias. Consellería de agricultura. Retrieved from http://www.xunta.es/conselle/ag.

Xunta de Galicia. (2000). Plan estratéxico de desenvolvemento económico de Galicia 2000 - 2006. Santiago de Compostela: Consellería de Economía e Facenda.

(Edited by Emily and Ann) 